
e-ISSN 2016/Atual: 2525-7870 | e-ISSN 2015/2016: 2447-018X

\title{
Análise Institucional com Foco na Docência: Um Relato de Experiência
}

\author{
Institutional Analysis Focusing on Teaching: Experience Report
}

\author{
Análísis Institucional Centrada en los Maestros: Um Relato de \\ Experiencia
}

\author{
Eslen Delagnore ${ }^{1}$ \\ João Paulo Perini ${ }^{2}$
}

Ma. Sabrina Alves de Souza ${ }^{3}$

Ma. Lizete Dieguez Piber ${ }^{4}$

\begin{abstract}
Resumo
Este artigo trata-se de um relato de experiência referente a um trabalho realizado na forma de Análise Institucional com um grupo de professores do turno da manhã de uma Escola Estadual de Ensino Fundamental localizada na região noroeste do Estado do Rio Grande do Sul. Com o objetivo de realizar um diagnóstico organizacional e proporcionar a possibilidade de uma autoanálise e autogestão da instituição, foram utilizadas observações e entrevistas semiestruturadas que posteriormente foram analisadas e relatadas em diários de campo. Com isso, proporcionou-se aos entrevistados a possibilidade de realizar uma reflexão a respeito de sua prática. Através da análise das entrevistas, percebeu-se que a problemática demandada da instituição diverge da problemática encontrada na análise, tornando evidente a presença de uma ideia errônea entre os membros da instituição em relação às atividades supostamente corretas exercitadas por eles. A experiência permitiu conhecer a força do instituído em uma instituição e modificar a postura do analista dentro da mesma.
\end{abstract}

Palavras-chave: Análise Institucional, Docência, Ensino, Instituição.

\section{Resumen}

Este artículo es un relato de experiencia en relación con una obra en forma de análisis institucional con un grupo de profesores de la mañana pasar de una escuela primaria de estado situado en la región noroeste de Rio Grande do Sul. Con el fin de llevar a cabo un diagnóstico de la organización y ofrecer la posibilidad de un

\footnotetext{
${ }^{1}$ Universidade Regional Integrada do Alto Uruguai e das Missões - URI, Santo Ângelo, Rio Grande do Sul; Brasil. dalenogare22@hotmail.com

${ }^{2}$ Universidade Regional Integrada do Alto Uruguai e das Missõe - URI, Santo Ângelo, Rio Grande do Sul;

Brasil.joao_perini@hotmail.com

${ }^{3}$ Mestrado em Educação; Universidade Regional Integrada do Alto Uruguai e das Missões - URI, Santo Ângelo, Rio Grande do Sul, Brasil. sabrina@urisan.tche.br

${ }^{4}$ Mestrado em Educação; Universidade Regional Integrada do Alto Uruguai e das Missões - URI, Santo Ângelo, Rio Grande do Sul, Brasil. lizeted@urisan.tche.br
} 

e-ISSN 2016/Atual: 2525-7870 | e-ISSN 2015/2016: 2447-018X

autoanálisis y autogestión de la institución a la que se utilizaron observaciones y entrevistas semiestructuradas fueron analizados posteriormente y se informó en el diario de campo. El propósito de las entrevistas era proporcionar a las personas la posibilidad de una reflexión sobre su práctica. A través del análisis de las entrevistas, se dio cuenta de que el problema exigía la institución se aparta de los problemas encontrados en el análisis, que apunta a la presencia de una idea equivocada entre los miembros de la institución en relación con las actividades supuestamente correctas hayan ejercido. La experiencia nos permitió conocer la fuerza del conjunto en una institución y modificamos la posición del analista en su interior

Palabras claves: Análisis Institucional, Enseñanza, Educación, Institución.

\section{Abstract}

This article is an experience report concerning a study in institutional analysis with a group of teachers of the morning shift from a primary state school located in the northwestern region of Rio Grande do Sul. In order to carry out an organizational diagnosis and provide the possibility of a self-analysis and self-management of the institution, were used observations and semi-structured interviews were subsequently analyzed and reported in field diaries. Thus, it brought to the interviewed the possibility of a reflection about their practices. Through the analysis of the interviews, it was realized that the problem demanded the institution diverges from problems found in the analysis, pointing to the presence of a mistaken idea among members of the institution in relation to supposedly correct activities exercised by them. The experience permitted to know the strength of the set in an institution and modify the analyst's position within it.

Keywords: Institutional Analysis, Teaching, Education, Institution.

\section{Introdução}

As questões relacionadas a uma área muito importante no campo da educação - a organização escola - tem tido uma crescente observação, reflexão e intervenção por parte dos estudantes e profissionais que nutrem interesses por essa área.

O presente trabalho propõe socializar os resultados de uma Análise Institucional realizada em uma instituição escola, onde os autores buscaram realizar um diagnóstico e posteriormente proporcionar ferramentas para a realização de uma autoanálise e autogestão, usando os precedentes da corrente teórica institucionalista.

Baremblitt nos diz que (1996, p.27)

As instituiçõos são lógicas, são árvores de composições lógicas que, segundo a forma e o grau de formalização que adotem, podem ser leis, podem ser normas e, quando não estão enunciadas de maneira manifesta, podem ser pautas, regularidades de comportamentos.

A manifestação de normas, leis, pautas, etc., se traduzem na instauração de uma cultura. Na escola, entre outras, os personagens que produzem essa cultura estão imersos em uma rotina instituída que impossibilita a mudança.

Através da distribuição dos papéis de cada sujeito na instituição, e posteriormente a apropriação dos mesmos, formam-se mecanismos que determinam as normas que deverão ser seguidas; um dos critérios geralmente é o saber. Quanto maior o saber do sujeito, maior o poder. 
A análise institucional pressupõe que as personagens de uma instituição estão à mercê desses atravessamentos institucionais que resultam em uma dificuldade em atingir os objetivos ou em alcançar o horizonte firmado nas propostas sociais e econômicas da instituição.

Portanto, concluímos através dos pressupostos institucionalistas, usando os escritos de Baremblitt (1996) que as instituições podem ser instituintes, pressupondo um modelo mais aberto e de livre pensamento ou instituídas, pressupondo um modelo mais tradicionalburocrático e rigoroso em normas e regras.

Durante a obtenção e observação dos dados, foram percebidas que as problemáticas da instituição não estavam de acordo com as problemáticas que foram diagnosticadas pelos analistas, demonstrando que a imersão no campo instituído não corrobora para uma avaliação imparcial, fazendo-se necessário para a efetividade da análise o auxílio de um observador de fora.

O objetivo desse artigo é relatar a experiência dos autores na condução de uma Análise Institucional realizada como proposta do Estágio Curricular do curso de Psicologia, levando em consideração as reflexões teóricas produzidas sobre o tema. Buscamos relatar os dados obtidos e socializar as dificuldades encontradas pressupondo a colaboração para os estudos e pesquisas na área.

\section{Metodologia}

As atividades de Análise Institucional ocorreram com um grupo de quatorze professores, seis alunos e quatro funcionários em uma Escola Estadual de Ensino Fundamental situada na região noroeste do estado do Rio Grande do Sul. A proposta ocorreu no período de Março até Junho de 2016, nas dependências da escola. A escola conta com uma diretora, duas coordenadoras, uma da manhã e uma da tarde e 29 professores. Comunicamos que nosso foco seria apenas os professores do turno da manhã. O turno da manhã compreende os alunos do quinto ao nono ano. A instituição engloba cerca de 300 alunos.

Nessa proposta usamos o método de observação, que, segundo Danna e Matos apud Cano e Sampaio (2007), mostra-se relevante, especialmente para entender o que os organismos fazem e sob quais circunstâncias. Lakatos apud Boni e Quaresma (2005, p.71), versa que "a observação consiste também em identificar e obter provas a respeito de objetivos sobre os quais os indivíduos não têm consciência, mas que orientam seu comportamento.”.

As observações tiveram como resultados diários de campos produzidos pelos observadores. Entendemos o diário de campo como uma ferramenta usada para registrar um 

e-ISSN 2016/Atual: 2525-7870 | e-ISSN 2015/2016: 2447-018X

recorte institucional observado e datado daquele dia específico, que posteriormente ajudará na análise dos dados registrados.

Além disso, os autores realizaram entrevistas semiestruturadas. Entendemos entrevistas semiestruturadas aquelas que "combinam perguntas abertas e fechadas, onde o informante tem a possibilidade de discorrer sobre o tema proposto." (BONI e QUARESMA, 2005, p.75).

Por fim, foram realizadas periódicas escutas clínicas; a importância desta se dá ao fato de que:

O exercício da escuta clínica, por sua vez, tem como perspectiva desvelar dimensões do cotidiano escolar e das relações que o estruturam até então impensadas, desconhecidas, mas que tangenciam as práticas que aí se estabelecem. (MARTINS, 2003, p.45).

As reflexões provocadas pelas entrevistas buscavam produzir uma autoanálise e uma autogestão nos sujeitos, sendo que autoanálise e autogestão são segundo Baremblitt (1996):

As comunidades mesmas, como protagonistas de seus problemas, de suas necessidades, de suas demandas, possam enunciar, compreender, adquirir ou readquirir um vocabulário próprio que lhes permita saber acerca de sua vida. E não que alguém venha de cima para dizer-lhes o quem são, de que necessitam e o que devem pedir, o que procurar conseguir e o que puderam ou não conseguir. Este processo de autoanálise das comunidades é simultâneo com o processo de auto organização, em que a comunidade se articula, se institucionaliza, se organiza para construir os dispositivos necessários para produzir, ela mesma, ou para conseguir os recursos que precisa para o melhoramento de sua vida sobre a terra. (p.17 e 18).

Implicitamente, essas observações e entrevistas com os professores foram analisadores artificiais, visando provocar uma fagulha de reflexão sobre suas próprias ideias e, através dessa análise pelos próprios integrantes do ambiente em que estão imerso, deu-se o início de uma autoanálise, que objetiva trazer sintomas do nível inconsciente para o nível consciente, tendo como ponte de transição a própria fala, assim denunciando os problemas e tentando a objetivar as subjetividades.

Entende-se analisador artificial como "dispositivos que os analistas institucionais inventam, introduzem nas organizações para propiciar o processo de explicitação dos conflitos e de resolução dos mesmos". (BAREMBLITT, 1996, p.72). Basicamente eles têm a função de explicitar o não dito. Nesse caso, os analisadores artificiais foram entrevistas com os atores das mais diversas áreas da instituição, com fim de absorver o máximo de dados possíveis e assim poder entender melhor como é o funcionamento da instituição. Ora, também 
foram observados os analisadores naturais, que consistem "analisadores históricos, ou seja, que a própria vida histórico-social-natural os produz por conta própria.” (BAREMBLITT, 1996, p.72).

\section{Discussão}

Objetivando proporcionar a autoanálise e a autogestão na instituição, entendemos que em um campo de intervenção, "pode-se entender sem intervir, mas não pode intervir sem entender" (BAREMBLITT, 1996, p.102). Portanto, adentramos-nos ao campo de análise, o qual foi o gerador da análise, e procuramos entendê-lo para conseguir criar mecanismos de intervenção.

Através de sua obra Baremblitt (1996) comenta que, apesar de existir um roteiro, uma análise institucional pode ser por si só incompleta e superficial devido sua complexidade e ampla dinâmica de aplicação. Devido a isso inclinamos uma atenção especial para esse trabalho.

Essa análise institucional, especificamente, encaixa-se na proposta de intervenção standard, isto é, "a mais habitual, a mais corriqueira, a mais conspícua." (BAREMBLITT, 1996, p.101).

Iniciamos com a análise da produção da demanda, que segundo Baremblitt (1996, p.106) "consiste no cuidadoso exame que a organização ou a pessoa que está para fazer a intervenção institucional faz, da maneira como ela ofereceu seus serviços, ou seja, o estudo da forma como ela produziu a demanda que lhe é feita". A análise da produção da demanda é vista quando a instituição solicitou a análise institucional com o intuito e queixa de que os alunos estavam com uma indisciplina comportamental incontrolável, portanto, a demanda oferecida pela instituição foi de que o problema estava nos alunos. Após realizarmos as entrevistas com os professores, percebemos que houve um equívoco quanto à demanda da instituição. Justifica-se isto através da constatação que alguns dos professores não estavam cientes da metodologia utilizada em suas aulas, denotando uma má compreensão sobre o porquê da indisciplina dos alunos, visto que os mesmos não eram estimulados à curiosidade. Isto veio a nos sugerir outra direção aos problemas, tirando o total foco dos alunos.

Entendemos a demanda consciente como sendo a demanda que a instituição apresenta. Essa demanda não é a real demanda, levando em consideração que ela pode ser facilmente inventada ou criada por um determinado setor da instituição, muitas vezes visando seus benefícios pessoais. $\mathrm{Na}$ experiência aqui socializada, os autores perceberam que a problemática demandada pela instituição fora a de que os alunos estavam com problemas de 

e-ISSN 2016/Atual: 2525-7870 | e-ISSN 2015/2016: 2447-018X

comportamento, entretanto, após a realização das entrevistas e observações, percebemos que a problemática era outra. Logo, usamos o exemplo supracitado para entender o encargo, que seria a demanda inconsciente; que é o que a instituição realmente está demandando, mesmo que não saiba.

A ideia errônea que os sujeitos têm em achar que todos os problemas podem ser resolvidos por eles mesmos favorece o aparecimento da dicotomia demanda consciente $\mathrm{x}$ demanda inconsciente. $\mathrm{O}$ que acaba deixando a instituição cega em relação às suas ansiedades e problemáticas e contribui para que o instituído se articule de forma silenciosa.

Quanto à produção da demanda por parte dos analistas, os autores tomaram o cuidado para não produzirem uma problemática dentro da instituição; igualmente, isso justifica o uso de entrevistas para obtenção dos dados, pois assim as respostas são puras e simples dos sujeitos, o que impede a intervenção dos analistas de forma ativa nos problemas, embora estejam intervindos de forma passiva, fazendo provocações através das perguntas para levar os sujeitos a reflexões.

Portanto, para poder dar o primeiro passo em toda análise de intervenção institucional - que é analisar a demanda - , esta análise deve ser articulada com a forma em que foi produzida, ou seja, com a oferta. Isso exige, por parte do coletivo analisante, o coletivo prestador de serviço, um severo processo de auto-análise de como produzir a oferta de seus trabalhos. (BAREMBLITT, Gregorio. 1996, p. 69)

$\mathrm{Na}$ análise de implicação, que não deixa de andar de mãos dadas com a demanda, percebeu-se que fora provocado um desconforto nos professores quando os autores aproximaram-se escola e comunicaram que o projeto iria envolvê-los. Lourau apud Rossi e Passos (2014, p.13) “desmembra o conceito de Análise da Implicação de acordo com a qualidade da relação estabelecida: Implicação Institucional se refere ao conjunto das relações entre o "ator" e as instituições".

Uma situação que mostrou esse incômodo da instituição em relação aos analistas apresenta-se quando fora realizada a devolução referente aos resultados obtidos nas entrevistas e uma das professoras levantou-se durante a reunião e retirou-se da sala, denotando sua impaciência com o trabalho realizado.

Houve a tentativa, por parte deles, de deturpar e direcionar o foco para outros problemas. Pereira (2007) alerta que:

Quando há uma prevalência do instituído, as instituições e seus estabelecimentos capturam os processos de subjetivação singulares, impondo-lhes seu próprio modelo através da centralidade do poder, do saber, do dinheiro, do prestígio, da 
disseminação da culpa. Por outro lado, quando as forças instituintes emergem, temse a possibilidade da produção de novos agenciamentos, novas composições e arranjos próprios de subjetividades livres e desejantes. (p.11)

O próximo passo fora averiguar a origem da solicitação do trabalho, o que caracteriza a análise da gestão parcial, isto é, "qual foi o setor da organização que assumiu o papel de vir consultar-nos ou fazer o contato" (BAREMBLITT, 1996, p.110). Nesse caso, quem procurou a análise foi o setor da direção. Segundo Baremblitt (1996) o grupo que solicita a analise geralmente é uma parte da instituição, nunca o todo, portando esse setor que solicita a análise da uma visão recortada da realidade, por esse motivo percebe-se a importância do analista entender o todo para manter-se imparcial e não deixar ser sugerido por partes.

Após analisado o discurso da direção e o discurso da instituição como um todo, notase que eles (direção) distribuíram estereótipos aos funcionários e aos professores.

Havemos de socializar que, depois de realizada as entrevistas e os as observações, entendemos que dentro da área da direção há uma dicotomia; há aqueles que querem atribuir a culpa a alguns sujeitos em especiais ou em algum grupo em especial, e há os sujeitos que têm consciência que estão inseridos no mesmo movimento e na mesma instituição, portando fazem parte, querendo ou não, da propriedade e da produção dos problemas que ali se encontram. Citamos o caso da coordenadora pedagógica responsável pela parte da manhã, onde ela tem consciência de que os problemas institucionais existem e que é necessário um movimento para modificar isso, e ela se coloca como integrante desse movimento causador desses problemas.

Obtivemos um encargo diferente da demanda. O encargo, que por definição, segundo Baremblitt (1996, p.111) é "a real demanda, que muitas vezes pode ser ocultada pela má fé ou pelo simples fato da instituição desconhecer o real problema".

O encargo não coincide com a demanda inicialmente verbalizada pela direção, logo se faz jus à literatura que o encargo é diferente da demanda, tendo como principal fator de prova à veracidade das informações, onde uma é demandada conscientemente, portando passível de distorção, e a outra, o encargo, é obsevada por alguém não imerso no instituído, portanto mais efetiva. Entretanto, falamos aqui que essa diferença não se dá apenas pela má fé, podendo ser fruto do desconhecido, por isso fez-se importante uma análise (Baremblitt 1996). O fator que demonstra a diferença do encargo e da demanda é o fato de que os professores e a instituição jogam toda a culpa dos problemas institucionais em terceiros, ou é a família do aluno que não ajuda, ou é os alunos que têm problemas psicológicos ou intelectuais, ou são desajustados e 
não aprendem. Observamos que eles, os professores, não se consideram e julgam que não influenciam na forma como ocorre o desdobramento dos problemas institucionais.

Uma das professoras atribuiu à falta de interesse dos alunos devida à sua desmotivação por consequência dos salários parcelados, o que podemos definir dentro dessa teoria como um analisador natural, que, segundo Baremblitt (1996, p.72) "são analisadores historico-socialnatural produzidos por conta própria."

O diagnóstico provisório é que os professores, no topo de suas torres de marfim, percebem o analista institucional como um sujeito que está ali para encontrar problemas dentro da instituição. Quando indagados sobre suas metodologias, percebemos que os professores produzem uma hierarquia conduzida pelo saber/poder, sendo que eles, como supostos detentores do saber, não aceitam estarem errados.

O mais preocupante é o fato da maioria dos professores não saberem qual a metodologia que utilizam em aula. Insistamos, eles colocam-se como donos do saber e os alunos são sujeitos passivos dentro dessa situação, onde os professores falam o que deve ser aprendido e os alunos fingem que aprendem. Esse desinteresse dos professores pela mudança, pela movimentação das ideologias e formas de ministrar aulas instituídas há anos gera, de maneira contaminadora, um desinteresse nos alunos.

“O passo seguinte consiste em, a partir desse diagnóstico provisório, poder planejar uma política, uma estratégia, uma tática e técnicas para começar sua intervenção." (BAREMBLITT, 1996, p 115).

O projeto obteve um resultado interessante na medida em que provocou uma modificação no pensamento de alguns sujeitos, que por consequência modificaram suas ações, passando de agentes passivos a agentes ativos dentro da instituição.

Concluí-se, de forma breve, através dessa experiência, que as demandas que achamos ter podem não ser condizentes com as reais necessidades de mudanças, justificando portanto a necessidade de uma análise institucional.

Por fim, deixo uma consideração que demonstra o quão genial e a complexo é uma análise:

A intervenção standard que tentei explicar tem milhares de variações, tanto que se pode dizer que a regra são as exceções. Mas, em todo caso, é um esquema para se considerar e omitir os passos que não sejam possíveis, que não sejam recomendáveis, condensar tantos outros etc. Em todo caso, é importante que cada interventor possa inventar um procedimento sui generis para cada situação. (BAREMBLITT, Gregorio, 1996, p.119). 


\section{Considerações Finais}

A instituição, embora tenha disponibilidade e interesse na análise, tentará, inconscientemente, repelir o analista do campo de analise, pois o analista tentará modificar a zona de conforto instaurada pelo instituído. Quando ameaçada - a zona de conforto - temos a presença de um movimento, de forma natural, que procura afastar o perigo. Esta tentativa de afastamento deve ser analisada e traduzida em estratégias e ferramentas que modificam os processos instituídos e transformam a instituição em uma organização instiuinte, e não instituída.

Nas próximas análises, devido à grande indisponibilidade de tempo dos professores, pensamos que seja indicado realizar uma intervenção mais inclinada para a área da gestão devido a maior disponibilidade de tempo e de acesso que a gestão tem aos professores.

Em termos gerais, a análise institucional demonstra uma aplicabilidade complexa, ampla e merece todo o cuidado. As mudanças ocorridas nos analistas e nas instituições analisadas proporcionam quebras de paradigmas, que podem ser entendidas, a primeiro ver, como algo maléfico, mas que em longo prazo produzem modificações benéficas..

\section{Referências}

BAREMBLITT, G. Compendio de Análise Institucional e outras correntes: teoria e prática. Rio de Janeiro: Rosa dos tempos, 1996.

BONI, Valdete e QUARESMA, Sílvia Jurema. Aprendendo a entrevistar: como fazer entrevistas em Ciências Sociais. 2005.

CANO, Debora Staub; SAMPAIO, Izabela Tissot Antunes. O Método de observação na psicologia: Considerações sobre a produção científica. Interações em psicologia, 2007.

MARTINS, João Batista. A atuação do psicólogo escolar: multirreferencialidade, implicação e escuta clínica. Psicol. estud., Maringá, v. 8, n. 2, p. 39-45, Dec. 2003. Available from $<$ http://www.scielo.br/scielo.php?script=sci_arttext\&pid=S1413-

$73722003000200005 \& \operatorname{lng}=$ en\&nrm=iso $>$. access on 24 Aug. 2016.

PEREIRA, William Cesar Castilho. Movimento institucionalista: principais abordagens. Estudos e pesquisa em psicologia. Abril de 2007.

ROSSI, André; PASSOS, Eduardo. Análise institucional: revisão conceitual e nuances da pesquisa-intervenção no Brasil. Rev. Epos, Rio de Janeiro, v. 5, n. 1, p. 156-181, jun. 2014. Disponível em <http://pepsic.bvsalud.org/scielo.php?script=sci_arttext\&pid=S2178700X2014000100009\&lng=pt\&nrm=iso>. acessos em 24 ago. 2016. sites). 